\title{
Variação e definição de queda de sílaba: o contexto segmental em Capivari-SP e Campinas-SP
}

\section{Variation and Definition of Syllable Drop: The Segmental Context in Capivari-SP and Campinas-SP}

\author{
Eneida de Goes Leal \\ Universidade de São Paulo, São Paulo, São Paulo / Brasil \\ CAPES \\ eneidaleal@yahoo.com
}

Resumo: Neste artigo, o objetivo é comparar o nível segmental de variação de queda de sílaba em duas cidades do interior de São Paulo, Capivari e Campinas, com base nos resultados da tese de Leal (2012). Decidiu-se por apresentar exclusivamente os resultados do contexto segmental porque é nesse nível fonológico que o processo é definido (LEAL, 2006, 2007). O trabalho foi fundamentado na geometria de traços (CLEMENTS; HUME, 1995) e na sociolinguística variacionista (cf. LABOV, 1972, 1994, 2001), aplicadas a um corpus de 48 entrevistas (24 em cada cidade). Os resultados revelam que consoantes coronais favorecem, e nasais desfavorecem o processo, em ambos os dialetos. No entanto, há uma grande diferença na implementação com dorsais: o processo é favorecido em Capivari e desfavorecido em Campinas. Quanto às vogais, pudemos verificar que há diferenças nas duas cidades, pois sequências [coronal + coronal] e [dorso-labial + coronal] são neutras em Capivari e favorecidas em Campinas. Também se constatou com os resultados que o OCP atua parcialmente no processo, já que rege a igualdade das consoantes, mas não das vogais. O que parece ser importante são as características da primeira sílaba - aquela sujeita ao 
apagamento. Finalmente, a análise conclui que a implementação da queda de sílaba se dá diferentemente nas duas cidades, no que concerne ao contexto segmental.

Palavras-chave: queda de sílaba; contexto segmental; sociolinguística variacionista; geometria de traços.

Abstract: The principal aim in this paper is to compare the segmental context in syllable drop variation (in two cities of São Paulo State countryside, Capivari and Campinas), a study which is part of Leal's (2012) dissertation. We have decided to show exclusively the results of the segmental context since this is the level in which the process is defined (LEAL, 2006, 2007). The theoretical background used was feature geometry (CLEMENTS; HUME, 1995), and variationist sociolinguistics (cf. LABOV, 1972, 1994, 2001), applied to a 48 interview corpus ( 24 from each city). The results show that coronal consonants favor the process and nasals disfavore it, in both of the dialects. However, there is great difference with dorsals: it is favored in Capivari and disfavored in Campinas. With regard to vowels, there are differences in the two cities, since [coronal + coronal] and [dorso-labial + coronal] sequences are neutral in Capivari and favored in Campinas. The results also revealed that OCP acts half way in the process, since it woks for consonants identity, but not for vowels. What seems to be relevant is the characteristics of the first syllable - the one that undergoes deletion. Finally, we conclude that syllable drop is different in the cities.

Keywords: syllable drop; segmental context; variationist sociolinguistics; feature geometry.

Recebido em 28 de setembro de 2016. Aprovado em 02 de dezembro de 2016.

\section{Introdução}

Neste artigo, tratamos do contexto segmental na variação de queda de sílaba (como sândi externo) em duas cidades do interior paulista, Capivari e Campinas. Os resultados aqui apresentados fazem parte da pesquisa de Leal (2012), tese de doutorado em que, a fim de comparar as interferências e características de queda de sílaba nas duas cidades, 
foram consideradas 14 variáveis internas e externas. ${ }^{1}$ Dessas variáveis, limitamo-nos a apresentar exclusivamente os resultados do contexto segmental, o que se justifica pela importância desse nível fonológico: é nele que o processo é definido ${ }^{2}$ (cf. seção 2). Dessa forma, podemos discutir esse nível fonológico com um detalhamento maior.

Entendemos que o termo 'queda de sílaba' pode ser usado como um hiperônimo, pois engloba outros dois processos: a elisão silábica e a haplologia, que serão definidos na seção $2 .{ }^{3}$

A organização do artigo foi feita da seguinte forma: na seção 1 , apresentamos as bases teóricas; em 2, está a literatura sobre a queda de sílaba no português brasileiro; na seção 3 , a metodologia; na seção 4, estão os resultados e a discussão, comparando-se as duas cidades; na quinta seção, estão as considerações finais, seguida das referências bibliográficas utilizadas.

\section{0 quadro teórico: pontos de diálogo}

Com o objetivo de verificar se a regra de queda de sílaba é a mesma em Capivari e Campinas, trabalhamos com a teoria gerativa, mais especificamente, com a geometria de traços (CLEMENTS; HUME, 1995), e com a sociolinguística variacionista (cf. LABOV, 1972, 1994, 2001).

Os pontos de diálogo entre os dois modelos são interpretados de acordo com a tendência (favorecimento, neutralidade ou desfavorecimento)

\footnotetext{
${ }^{1} \mathrm{Na}$ tese, foram utilizados 4 grupos de fatores linguísticos do contexto segmental apresentados neste artigo (cf. seção 3), mais outros 5 grupos de fatores linguísticos (Estrutura Silábica, Métrica, Prosódia, Número de Sílabas e Frequência de Uso de Palavras) e 5 grupos de fatores sociais (Escolaridade, Gênero, Faixa Etária, Informante e Cidade) - cf. Capítulo IV de LEAL (2012).

${ }^{2}$ Outros níveis fonológicos da queda de sílaba podem ser verificados em LEAL (2012).

${ }^{3}$ A escolha de Capivari foi feita com base nos resultados obtidos na dissertação de mestrado de LEAL (2006, 2007): o contexto segmental de queda de sílaba é mais abrangente (em termos de traços fonológicos) nessa cidade do que aqueles reportados na literatura (cf. ALKMIM; GOMES, 1982; BATTISTI, 2004, 2005; SIMIONI; AMARAL, 2012; PAZ, 2013; OLIVEIRA; PAZ, 2013; TENANI, 2002). E Campinas foi a segunda cidade eleita porque ambas estão próximas (54 quilômetros), e os informantes apresentam o fenômeno nos moldes em que ele é descrito pela literatura, o que possibilitou a comparação (cf. detalhamento do estudo piloto com falantes de capivarianos e campineiros na subseção 5.1 de LEAL, 2012).
} 
e à produtividade (expressos via frequência de aplicação e peso relativo) dos diferentes contextos possíveis das regras (definidos pela fonologia gerativa, isto é, igualdade na cavidade oral - cf. seção 2). Para que a comparação fosse feita de forma objetiva, seguimos estes critérios para interpretar os resultados nas duas cidades:

- Iguais: são fatores que têm a mesma tendência nas duas cidades, e a diferença entre os pesos relativos são pequenas - isto é, há uma mesma tendência e produtividade da regra;

- Semelhantes: dentro de uma mesma variável, há um fator (es) com comportamento (s) idêntico(s) nas duas cidades (o que significa ter uma mesma tendência), mas a produtividade é diferente, ou seja, pode ser que um fator seja aplicado mais vezes numa cidade do que na outra; e

- Diferentes: são os fatores com tendências diferentes nas duas cidades (por exemplo, favorecimento versus desfavorecimento, desfavorecimento versus neutralidade, favorecimento versus neutralidade etc.) e, consequentemente, a produtividade também é diferente. Adicionalmente, consideramos diferentes as variáveis que foram selecionadas numa cidade e não em outra, dado que, se uma variável é selecionada, podemos interpretar que aquela variável condiciona o processo e, de modo contrário, uma variável não selecionada indica que um conjunto de fatores não exerce qualquer efeito no processo.

Com base em Leal (2006, 2007), os traços mais importantes para a definição do processo aqui em estudo (cf. seção 2) são os nós irmãos Ponto de $\mathrm{C}$ e [contínuo] das consoantes, ambos dominados pelo nó Cavidade Oral (cf. representação arbórea em CLEMENTS; HUME, 1995, p. 276). Assim, a queda de sílaba deve "olhar" internamente para a Cavidade Oral das consoantes para identificar a igualdade entre os traços internos nas consoantes; se houver semelhança, a queda de sílaba pode ser aplicada, isto é, há variação do processo.

A principal justificativa para se utilizar a geometria de traços como base de análise da queda de sílaba é a possibilidade de se descrever consoantes e vogais de um mesmo modo, pois esses dois segmentos contêm os traços [coronal], [labial] e [dorsal]. Assim, será possível 
verificar se um mesmo traço tem um comportamento semelhante para a queda de sílaba nas duas cidades.

Uma vez apresentado o quadro teórico e as questões que buscamos, na seção a seguir, apresenta-se a literatura de queda de sílaba.

\section{A literatura sobre a queda de sílaba e a definição do processo ${ }^{4}$}

Os estudos sobre a queda de sílaba no português brasileiro (PB) não são novos. Sá Nogueira (1958), por exemplo, já apresenta definições desse processo fonológico; ainda, uma das referências mais constantes neste trabalho é de mais de 30 anos (cf. ALKMIM; GOMES, 1982). De modo geral, a queda de sílaba é definida como um processo fonológico em que a adjacência de duas sílabas com unidades internas iguais ou semelhantes resulta em apenas uma delas no output. Segundo Leal (2006), a depender de quão semelhantes são as unidades internas, a expressão "queda de sílaba" pode ser usada como um hiperônimo, pois engloba outros dois processos fonológicos: a elisão silábica e a haplologia. O primeiro é um processo mais abrangente (em termos de traços fonológicos) do que a haplologia, mas, já que há mais trabalhos sobre esse último processo, iniciaremos as definições por ele. Observe os exemplos a seguir: 5

$\begin{array}{llll}\text { (1) } / \mathrm{t}+\mathrm{d} / & \text { na fren(TE) DE casa } & \sim & \text { na frenTE DE casa } \\ \text { (2) } / \mathrm{t}+\mathrm{t} / & \text { quan(TO) TRAbalho } \sim & \text { quanTO TRAbalho }\end{array}$

Os exemplos (1) e (2) são canônicos, pois todos os autores de que tenho ciência (ALKMIM; GOMES, 1982; BISOL, 2000; TENANI, 2002; BATTISTI, 2004, 2005; PAVEZI, 2006; LEAL, 2006, 2007, 2012; MENDES, 2009; SIMIONI; AMARAL, 2011; OLIVEIRA, 2012; PAZ, 2013; OLIVEIRA; PAZ, 2013; OLIVEIRA; VIEGAS, 2013) concordam que o contexto consonantal com /t/ ou /d/ é favorável à aplicação de queda de sílaba - ou seja, deve ser um dos contextos /t + t/,/t + d/, /d +

\footnotetext{
${ }^{4}$ As referências aqui apresentadas dizem respeito ao português brasileiro; para o processo em outras línguas, cf. referências no Capítulo III em LEAL (2012).

${ }^{5}$ Seguimos o IPA (International Phonetic Alphabet) para as transcrições, os parênteses assinalam apagamento de segmento(s), e os contextos de queda de sílaba estão marcados em maiúsculas.
} 
$\mathrm{d} / \mathrm{ou} / \mathrm{d}+\mathrm{t} /$. Uma vez que a única diferença entre as consoantes em (1) é [vozeamento], há possibilidade de haplologia; em (2), as consoantes são idênticas $/ \mathrm{t}+\mathrm{t} /$, e o processo também pode ser aplicado. Ambos os exemplos (1) e (2) são casos de haplologia, uma vez que a diferença máxima entre as consoantes está no traço vozeamento.

Alkmim e Gomes (1982, p. 51) propõem os seguintes critérios segmentais para que haja a possibilidade de apagamento da sílaba: ${ }^{6}$

(3) Contexto segmental da haplologia para Alkmim e Gomes (1982):

(i) a primeira e a segunda consoantes devem ser coronais [-contínuo, oral] (ou seja, são necessariamente /t/ ou /d/);

(ii) a primeira vogal deve obrigatoriamente ter o traço [+alto]; e

(iii) a segunda vogal e seus traços internos não importam.

Alkmim e Gomes (1982) explicam que se as consoantes forem diferentes de /t/ e /d/, um processo possível é a elisão vocálica, e nunca a haplologia, exemplificado pelas autoras com saBE BEIjar (ALKMIM; GOMES, 1982, p. 48):
a) elisão vocálica: $\mathrm{saB}(\mathrm{E}) \mathrm{BEIjar}$
b) adjacência de Cs: saBBEIjar ['sab:ej'za]

haplologia: *sa(BE) BEIjar *['sabej'za] $]^{7}$

Por ser diferente de /t, d/, o único processo possível em (4) e (5) para Alkmim e Gomes (1982) é o apagamento da primeira vogal (cf. (4) a), o que acarreta a adjacência de duas consoantes iguais, que ficam alongadas no output (cf. (4) b); com esse contexto consonantal /b + b/, a haplologia é bloqueada, como se vê em (5). Esse ponto de vista de que a haplologia só é possível com contextos consonantais / $\mathrm{t}$, $\mathrm{d}$ / é sustentado também por Tenani (2002), Battisti (2004, 2005), Simioni e Amaral (2011), Paz (2013) e Oliveira e Paz (2013).

\footnotetext{
${ }^{6}$ Alkmim e Gomes apresentam outras restrições que não estão apresentadas aqui porque não são sobre contexto segmental (cf. ALKMIM; GOMES, 1982, p. 51).

${ }^{7}$ Usamos o asterisco para indicar a agramaticalidade da sentença ou do sintagma (neste artigo, "agramatical" significa "categórico para não ser aplicado").
} 
O primeiro trabalho que apresenta contextos consonantais de haplologia diferentes de coronais [-contínuo] é Bisol (2000). Como o intuito da autora é verificar a relação entre ritmo e processos fonológicos, ela não trata de contextos segmentais, mas apresenta o seguinte exemplo de haplologia (p. 409):

(6) $/ \mathrm{k}+\mathrm{k} / \quad \mathrm{O}$ macaCO COmeu todas as bananas $>$ maca(CO) COmeu

Como vemos em, há a possibilidade de queda de sílaba com o contexto consonantal $/ \mathrm{k}+\mathrm{k} /$ para Bisol (2000), ou seja, um contexto diferente da definição de Alkmim e Gomes (1982).

Nos exemplos abaixo, estão outros estudos que apresentam resultados com características consonantais diferentes de Alkmim e Gomes (1982) e as respectivas cidades estudadas.

(7) $/ \mathrm{n}+\mathrm{n} / \quad$ pisci(NA) NO verão (PAVEZI, 2006) São Paulo-SP

(8) $/ v+v / \quad$ fica(VA) VIAjando (LEAL, 2006, 2007) Capivari-SP

(9) $/ \mathrm{p}+\mathrm{p} / \quad$ uns tem(POS) PRA cá (MENDES, 2009) B. Horizonte-MG

(10) /g + k/ meu cole(GA) QUE não ia (OLIVEIRA, 2012) Itaúna-MG

Nos exemplos (7)- , as consoantes de cada contexto têm, no máximo, a diferença no traço de [vozeamento], o que caracteriza a haplologia - nesses casos, os contextos são diferentes de $/ \mathrm{t}, \mathrm{d} /$, e o processo pode ser aplicado.

Como dito anteriormente, a haplologia é um processo muito estudado na literatura e é mais específico do que a elisão silábica, já que, naquele processo, a diferença máxima entre as consoantes deve ser o traço [vozeamento]. Para a elisão silábica, observe os exemplos a seguir.
(11)
$/ \mathrm{t}+\mathrm{n} /$
de jei(TO) NEnhum
de jeiTO NEnhum
(12) $/ z+3 /$
bele(ZA) GIgantesca
beleZA GIgantesca

Em (11), o contexto $/ \mathrm{t}+\mathrm{n} /$ é formado por duas consoantes coronais [-contínuo, +anterior, -distribuído], em que a primeira é um segmento oral [-vozeado], e a segunda é uma nasal [+vozeado], e a 
queda de sílaba pode ser aplicada. ${ }^{8}$ No contexto $/ z+3 /$ em (12), há duas coronais [+contínuo, +vozeado], e há aplicação do processo, mesmo que /z/ seja [+anterior, -distribuído] e /3/ seja [-anterior, +distribuído]. ${ }^{9}$ Contudo, a elisão silábica não é um processo fortuito, já que o contexto consonantal é definido. Observe os exemplos a seguir de Leal (2006):
(13) $/ \mathrm{k}+\mathrm{p} / \quad *$ mole(QUE) POderoso
(p. 90)
(14) $/ \mathrm{s}+\mathrm{d} /{ }^{*}$ crian(ÇA) DIfícil
(15) $/ \mathrm{d}+\mathrm{v} /$
*pare(DE) VERmelha

Em casos como (13), há dois segmentos [-contínuo] $/ \mathrm{k}+\mathrm{p} /$, mas o ponto de $\mathrm{C}$ das consoantes é diferente (há uma dorsal seguida de uma coronal); em (14), há duas coronais $/ \mathrm{s}+\mathrm{d} /$, sendo que a primeira é [-vozeado, +contínuo, +anterior, -distribuído], e a segunda é [+vozeado, -contínuo, +anterior, -distribuído]; finalmente, no exemplo (15), há diferenças tanto no ponto de $\mathrm{C}$ quanto em [contínuo] nas consoantes, já que /d/ é uma coronal [-contínuo] e /v/ é uma labial [+contínuo]. Nos três exemplos (13)-(15), apagar a sílaba torna o sintagma agramatical em Capivari (LEAL, 2006, 2007).

Até o momento, apresentamos as características das consoantes da queda de sílaba e, para as vogais, também não há consenso na literatura: Alkmim e Gomes (1982, p. 50) afirmam que somente há haplologia se a primeira vogal do contexto tiver o traço [+alto]. Assim, para as autoras, nos contextos segmentais abaixo, há possibilidade de aplicação de haplologia.
(16) $/ \mathrm{e}+\mathrm{e} />[\mathrm{i}+\mathrm{i}]$
limiTE DE palavra $>$ limi(TE) DE palavra
(17) $/ o+e />[u+i]$
calDO DE cana > cal(DO) DE cana

Como se observa em (16) e , a representação do contexto vocálico de Alkmim e Gomes (1982, p. 48) é feito foneticamente, com vogais que

\footnotetext{
${ }^{8}$ Observe que as nasais são [+contínuo] na cavidade nasal, mas, na oral, são segmentos [-contínuo].

${ }^{9}$ Veja que os traços [ \pm anterior, \pm distribuído] se aplicam somente às coronais, já que são nós irmãos dependentes do traço [coronal], que está abaixo desse nó na geometria (cf. CLEMENTS; HUME, 1995, p. 292).
} 
carregam o traço [+alto] nesse nível. No exemplo a seguir, a aplicação de haplologia é agramatical segundo as autoras (p. 50), já que a dorsal /a/ tem o traço [+baixo]:

(18) comiDA DO Líbano > *comi(DA) DO Líbano

Entretanto, Pavezi (2006) e Leal (2006, 2007) encontraram em seus resultados aplicação de haplologia tanto com vogais altas quanto com vogais baixas, como se observa nos exemplos a seguir.

$\begin{array}{lll}\text { (19) } / \mathrm{a}+\mathrm{a} / & \text { esca(DA) DAnificada } & \text { (PAVEZI, 2006, p. 116) } \\ \text { (20) } / \mathrm{a}+\mathrm{e} / & \text { estra(DA) DE terra } & \text { (LEAL, 2006, p. 101) }\end{array}$

Como podemos notar nesses exemplos (19) e , para Pavezi (2006) e Leal $(2006,2007)$, a queda da sílaba é possível em contextos em que a primeira vogal é uma dorsal, diferentemente do que afirmam Alkmim e Gomes (1982).

Há ainda dois aspectos que devem ser considerados sobre a queda de sílaba. O primeiro é distinguir esse processo do truncamento: nesse último, a perda de segmentos e/ou sílabas pode acontecer independentemente de contexto segmental, e a palavra pode ser reduzida mesmo quando produzida antes de pausa, como nos exemplos (Parque da) Redenção $>$ Redença, feijoada $>$ fejuca. Dessa forma, queda de sílaba e truncamento são processos fonológicos distintos, como exemplificado a seguir.

(21) a) aplicação de elisão silábica $\rightarrow$ faculda(DE) NO centro

b) aplicação de haplologia $\rightarrow$ faculda(DE) DO centro

(22) aplicação de truncamento $\rightarrow$ faço facul //

(23) bloqueio de elisão silábica $\rightarrow$ *faço faculda(DE) //

Em (21), há variação de queda de sílaba porque os contextos consonantais a) $/ \mathrm{d}+\mathrm{n} / \mathrm{e}$ b) $/ \mathrm{d}+\mathrm{d} /$ são favoráveis ao apagamento: em (21) a), há duas coronais [+vozeado, -contínuo] e, em (21) b), há duas coronais [+vozeado, -contínuo], sendo que a primeira é oral e a segunda é nasal; no exemplo (22), o processo é o truncamento, mesmo que depois 
da redução haja uma pausa (indica por // nos exemplos); e, em (23), a elisão silábica é categórica para nunca acontecer, uma vez que há uma pausa depois de faculdade, o que impede o apagamento da sílaba.

Um segundo aspecto sobre a queda de sílaba, com opiniões divergentes na literatura, diz respeito à natureza do processo. Bisol (2000), Oliveira (2012) e Oliveira e Viegas (2013) defendem que a aplicação de haplologia se dá em duas partes, seguindo-se Sá Nogueira:

Os fenômenos de haplologia consideram-se em regra casos de síncope de uma sílaba.

Isto, porém, salvo erro, não é certo: na realidade não há ali uma supressão pura e simples de uma sílaba; o que há é uma síncope [...] do vogal [sic] da primeira de duas sílabas iguais ou semelhantes, seguida da geminação de dois consoantes [sic] que passam a ficar em contacto, os quais se mantêm geminados ou se fundem num só.

Na pronúncia despreocupada do vocábulo filologia, por ex., ouve-se umas vezes fil-lo-gia, e outras filogia.

Na de Campo Pequeno também se ouve umas vezes camppequeno, e outras campequeno.

De saudadoso deve ter-se passado primeiro a saud-doso e daqui a saudoso. (SÁ NOGUEIRA, 1958, p. 180, grifos do autor).

Assim, há duas etapas na haplologia: na primeira, há elisão da vogal; e, na segunda etapa, por estarem adjacentes, as consoantes podem geminar. Então, a haplologia teria uma natureza tanto de apagamento (da vogal), quanto de coalescência (de consoantes).

Por outro lado, Alkmim e Gomes (1982), Tenani (2002), Battisti (2004, 2005), Pavezi (2006), Mendes (2009), Leal (2006, 2007, 2012), Paz (2013) e Oliveira e Paz (2013) afirmam que ocorre o apagamento da primeira sílaba. Seguimos, neste artigo, essa segunda interpretação, ou seja, de que há apagamento da sílaba toda, fundamentada nos resultados Battisti (2005). ${ }^{10}$ Além desse trabalho, entendemos que há casos em que a coalescência da primeira e da segunda sílabas parece não se revelar no output, como no exemplo a seguir, bastante comum na literatura (cf.

\footnotetext{
${ }^{10}$ A análise de haplologia de Battisti (2004) foi feita com base na Teoria da Otimalidade (PRINCE; SMOLENSKY, 1993), e seus resultados mostram que há apagamento da primeira sílaba, desencadeado pelo OCP.
} 
BATTISTI, 2004, p. 31; BATTISTI, 2005, p. 81; LEAL, 2006, p. 62; MENDES, 2009, p. 25; OLIVEIRA; PAZ, 2013, p. 78; PAVEZI, 2006, p. 33; PAZ, 2013, p. 30-31):

(24) $/ \mathrm{tr}+\mathrm{d} / \quad \operatorname{denTRO}$ DE... $>\operatorname{den}(\mathrm{TRO}) \mathrm{DE} \ldots$

Em (24), só pode haver apagamento da primeira sílaba: esse é um dos exemplos que, como afirma Battisti, mostra "claramente que o material fonológico que se realiza no output é o da sílaba da direita." (BATTISTI, 2004, p. 32). Entendemos que o problema de se considerar a haplologia como coalescência se explica pelo fato de esse processo indicar a convergência de unidades linguísticas, originalmente separadas, que antes podiam ser distinguidas (CRYSTAL, 2003 [1985], p. 49, 123). Por exemplo, na palavra /eu/ropa, em alguns dialetos brasileiros, as vogais /eu/ podem se fundir, formando um único segmento [o] no output, [o]ropa. Podemos observar que, no resultado da fusão [o], há traços de ambos os segmentos subjacentes /e/ e /u/:

(25) Fusão entre $/ \mathrm{e}+\mathrm{u} />[\mathrm{o}]$

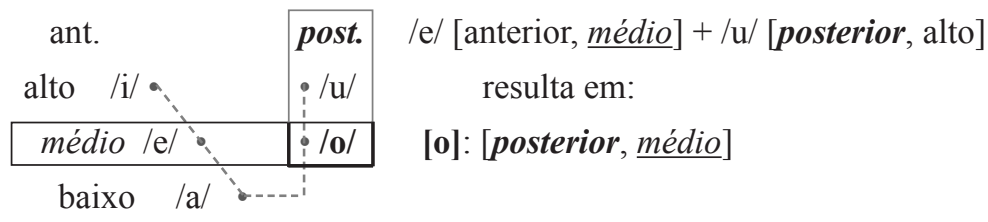

Dessa forma, assumimos que a queda de sílaba se dá por apagamento, e não por fusão de unidades fonológicas; um resultado de coalescência entre as consoantes /tr/ e /d/ no exemplo (24) deveria levar em conta também os traços de $/ \mathrm{r} /$ do ataque ramificado, do mesmo modo como se considerou /eu/ropa $>$ [o]ropa.

Em vista dos exemplos apresentados em (1) e (2) e em - desta seção, podemos concluir que, segmentalmente, a diferença entre a haplologia e a elisão silábica é que, no primeiro processo fonológico, as consoantes do contexto podem ser iguais ou semelhantes (e, nesse caso, a diferença é, no máximo, no traço [vozeamento]), enquanto que, no segundo, as consoantes podem ser diferentes também nos traços [anterior, distribuído] e [nasal] (cf. LEAL, 2006, p. 161).

Ainda que os traços internos às consoantes possam dividir a queda de sílaba em haplologia e elisão silábica, ambas são tratadas neste artigo 
como um único processo, já que têm as mesmas propriedades segmentais (cf. LEAL, 2006, 2007 e o estudo piloto realizado no corpus de LEAL, 2012), prosódicas e métricas (ver LEAL, 2006) - e usamos "queda de sílaba" como um hiperônimo de "elisão silábica" e de "haplologia".

A definição geral de aplicação de queda de sílaba é a seguinte: as consoantes do contexto devem ter o mesmo ponto de C e o mesmo valor para o traço [contínuo] (cf. LEAL, 2006, p. 165).

Na próxima seção, apresentamos a metodologia empregada nesta pesquisa.

\section{Metodologia}

No corpus, há 48 gravações ${ }^{11}$ de 1 hora cada, com 24 informantes de Capivari e 24 de Campinas. ${ }^{12}$ Foram utilizados 50 minutos de cada gravação, e a obtenção de todos os dados foi feita diretamente no Praat (BOERSMA; WEENINK, 2010); a frequência default de visualização dos sons foi $6 \mathrm{kHz}$ (variando, por exemplo, com as fricativas, vozes femininas), e a resolução na tela variou de 0,5 a 1 segundo, aproximadamente. A cada contexto de queda de sílaba, a janela era diminuída para a faixa de 0,5 a 1 segundos, e foram marcados nos arquivos de text grid o tempo da ocorrência e também os segmentos relevantes. Portanto, todos os

\footnotetext{
11 Nas entrevistas, os diálogos foram conduzidos de tal forma que as conversas se dessem de maneira informal, e os tópicos das entrevistas foram, basicamente, cinco: infância, adolescência, namoro/casamento, trabalho, ponto de vista do informante com relação à sua cidade natal (como era, como está hoje em dia), buscando-se o vernáculo (LABOV, 1972, p. 208).

${ }^{12}$ Para extrair os dados do corpus, foram feitas as seguintes restrições: 1) deve haver pelo menos uma consoante no ataque das sílabas, já que contextos $\mathrm{V} \# \mathrm{~V}$ podem produzir outros processos fonológicos, como em gaTA EScura>gaT[I]Scura (nesse exemplo, o processo aplicado é a elisão vocálica); 2) empréstimos foram codificados de acordo com a fonologia do português, como em internet $>$ /inter'ncte/; 3) os contextos segmentais têm uma mesma cavidade oral para as consoantes, uma vez que, se forem diferentes, a aplicação é categórica (cf. seção 2); 4) a primeira sílaba deve ser fraca (cf. TENANI, 2002) computamos somente falas neutras (hesitação, ênfase; momentos em que o informante riu não foram computados); 6) a frase entonacional (cf. NESPOR; VOGEL, 1986) foi usada para limitar uma ocorrência; e 7) casos de apagamento do clítico não foram analisados, como no exemplo posTO DE SAúde, que foi realizado como pos(TO DE) saúde, por uma falante capivariana.
} 
contextos de queda de sílaba da tese foram checados nos espectrogramas (cf. metodologia ao verificar se toda a sílaba foi elidida ou parte dela em Leal (2012, p. 79-81).

A variável dependente analisada é binária, com as variantes aplicação e não aplicação do processo. ${ }^{13}$ Quanto às variáveis independentes do contexto segmental, ${ }^{14}$ foram 4 configurações estudadas: Igualdade de Segmentos, Cavidade Oral das Consoantes, Cavidade Oral das Consoantes com Distinção do Traço [nasal] e Cavidade Oral das Vogais.

Para Igualdade de Segmentos nas Sílabas CV, ${ }^{15}$ os fatores estão apresentados a seguir, com um exemplo de aplicação de queda de sílaba em cada um deles ${ }^{16}$ (os símbolos à esquerda são utilizados para apresentar os resultados nas tabelas e gráficos da seção 4).

1. $\mathrm{C}=\mathrm{V}=\quad \mathrm{Cs}$ iguais, Vs iguais apren(DE) DEsenho

2. $\mathrm{C}=\mathrm{V} \# \quad \mathrm{Cs}$ iguais, Vs diferentes apareci(DA) DO norte

3. $\mathrm{CH}$ vozV $=$ Cs diferentes em [vozeamento], Vs iguais ajudan(TE) DE pintor

4. C\#vozV\# Cs diferentes em [vozeamento], Vs diferentes mui(TO) DIfícil

5. $\mathrm{C} \#$ nasalV $=\mathrm{Cs}$ diferentes em [nasal], Vs iguais conversan(DO) NO telefone

6. C\#nasalV\# Cs diferentes em [nasal], Vs diferentes chegar nu(MA) POsição melhor

7. C\#distr. Cs diferentes em [anterior, distribuído] $]^{17} \quad$...laçar cabe(ÇA). JÁ vamo?

A primeira hipótese para essa variável tem como base o Princípio de Contorno Obrigatório (OCP - Obligatory Contour Principle): ${ }^{18}$ na

\footnotetext{
${ }^{13}$ A análise dos dados foi feita com a ferramenta estatística GoldVarb X (cf. SANKOFF; TAGLIAMONTE; SMITH, 2005).

${ }^{14} \mathrm{Cf}$. nota 2

${ }^{15}$ Para essa variável, não foram computadas estruturas diferentes de CV; a estrutura silábica foi uma variável controlada à parte (cf. LEAL, 2012).

${ }^{16}$ Apresentamos apenas aplicações do processo nos fatores, mas trata-se de variações com cada um dos contextos apresentados. Os exemplos nesta seção são todos de Leal (2012).

${ }^{17}$ Neste fator, não distinguimos as vogais porque os dados não tiveram uma distribuição ortogonal (consoantes diferentes em [anterior, distribuído], com vogais iguais, $\mathrm{N}=2 / 28$; com vogais diferentes, houve knockout, $\mathrm{N}=0 / 27$ ).

${ }^{18}$ O OCP foi primeiramente proposto por Leben (1973), em estudos de línguas tonais, e muitos outros autores trabalham com o princípio (cf. McCARTHY, 1979, GOLDSMITH,
} 
queda de sílaba, se houver duas sílabas idênticas, o princípio é acionado, e o apagamento da primeira delas resolve a questão. Então, a expectativa é que, quanto mais parecidas segmentalmente forem as sílabas, maior é a probabilidade de aplicação do processo. Nos fatores apresentados anteriormente, a hipótese é que haja maior propensão à queda de sílaba nos fatores 1,3 e 5 (já que as vogais são idênticas) se comparados com 2, 4 e 6, com vogais diferentes.

Outras hipóteses dizem respeito aos traços internos às consoantes: para [vozeamento], a expectativa é que esse traço não tenha interferência na haplologia (cf. ALKMIM; GOMES, 1982, TENANI, 2002, BATTISTI, 2004, PAVEZI, 2006; e LEAL, 2006) e nem mesmo na elisão silábica no sentido de bloquear o processo (cf. LEAL, 2006). Dessa forma, se [vozeamento] atuar na queda de sílaba, haverá uma diferença na tendência entre os fatores 1 e 2 e também entre 3 e 4; se esse traço não interferir, a tendência entre os fatores 1-2 e 3-4 deve ser a mesma. A terceira hipótese diz respeito ao traço [nasal], ${ }^{19} \mathrm{em}$ que pode haver aplicação de queda de sílaba com nasais, com base em Pavezi (2006) e Leal (2006); adicionalmente, isolamos esses segmentos a fim de observar como eles podem influenciar na aplicação do processo. A quarta hipótese está relacionada aos traços que estão abaixo de [coronal], com o propósito de investigar como os traços [anterior, distribuído] interferem no processo.

Com relação às vogais, a cada especificação diferente de consoantes, propusemos também vogais iguais e diferentes, a fim de examinar se as vogais também intervêm no processo.

O segundo grupo de fatores proposto foi Cavidade Oral das Consoantes, codificando-se a primeira e a segunda consoantes de acordo com suas cavidades orais (ponto de $\mathrm{C}$ e valor para [contínuo]). A hipótese criada para essa variável é que haja uma maior tendência à aplicação com coronais, uma vez que essas consoantes são subespecificadas em diversas línguas (cf. PARADIS; PRUNET, 1991; FIKKERT; LEVELT, 2006) e, especificamente no $P B$, estudos reportam que é com $/ \mathrm{t} / \mathrm{e} / \mathrm{d} /$ que

1990). McCarthy (1988, p. 88) reformulou-o do seguinte modo: "Elementos idênticos adjacentes são proibidos" (Adjacent identical elements are prohibited). Assim, essa reformulação dá conta de traços, segmentos, tons, sílabas, etc.

${ }^{19}$ Lembramos que, para haver variação, o contexto consonantal deve ter uma mesma cavidade oral; assim, todos os contextos nasais neste artigo são formados por consoantes que têm um mesmo ponto de $\mathrm{C}$ e um mesmo valor para [contínuo]. 
a queda de sílaba ocorre (ALKMIM; GOMES, 1982; BATTISTI, 2004, 2005; SIMIONI; AMARAL, 2011; PAZ, 2013; OLIVEIRA; PAZ, 2013; TENANI, 2002). Foram propostos os seguintes fatores:

1. $\mathrm{t}+\mathrm{t}$ duas Cs coronais [-contínuo]

2. $\mathrm{s}+\mathrm{s}$ duas Cs coronais [+contínuo]

3. $\mathrm{p}+\mathrm{p}$ duas Cs labiais [-contínuo]

4. $\mathrm{f}+\mathrm{f}$ duas Cs labiais [+contínuo]

5. $\mathrm{k}+\mathrm{k} \quad$ duas $\mathrm{Cs}$ dorsais ${ }^{20}$
faculda(DE) DE letras

a polí(CIA) CHEgou

tem(PO) PRA aposentadoria

não ta(VA) FAzendo nada de errado

lógi(CO) QUE não

\section{A terceira variável investigada foi Cavidade Oral das}

Consoantes com Distinção de [nasal] com os seguintes fatores:

1. $\mathrm{t}+\mathrm{t}$ duas Cs coronais orais [-contínuo]

2. $\mathrm{s}+\mathrm{s}$ duas Cs coronais orais [+contínuo]

3. $\mathrm{p}+\mathrm{p}$ duas Cs labiais orais [-contínuo]

4. $\mathrm{f}+\mathrm{f}$ duas Cs labiais orais [+contínuo]

5. $\mathrm{k}+\mathrm{k}$ duas Cs dorsais

6. $\mathrm{n}+\mathrm{n} \quad$ uma ou duas Cs nasais (com mesma cavidade oral)

Os fatores 1-5 são os mesmos daqueles apresentados na variável Cavidade Oral das Consoantes, e a única diferença é que nasais foram separadas no fator 6, como em va(MOS) MARcar? e deita(DO) NO hão. Decidimos analisar o comportamento das nasais com base em Pavezi (2006) e Leal (2006), para quem há possibilidade de queda de sílaba com esses segmentos. Não temos uma hipótese formulada para essa variável que vá além daquela apresentada na subseção anterior (por sua subespecificação, as coronais são as consoantes mais elididas), mas pretendemos verificar como se comportam também as nasais, assim como

\footnotetext{
${ }^{20}$ Todas as consoantes dorsais encontradas no corpus são [-contínuo] - /k/ e /g/. Nas duas cidades, o /r/ forte em rato pode ser produzido como [h], uma laringal [+contínuo, -vozeado], como em [h]ato; ou como [x], uma dorsal [+contínuo, +vozeado], como em [x]ato. No entanto, esse tipo de contexto $/ r+r /$ forte não foi encontrado no corpus. Assim, já que a outra possibilidade de dorsais [x] para o português brasileiro [+contínuo] não apareceu no corpus, deste ponto em diante, o valor de [contínuo] para dorsais não será mais indicado - será sempre uma dorsal [-contínuo].
} 
verificar qual das configurações de consoantes (sem separar as nasais ou colocando-as num fator à parte) é mais relevante para a aplicação do processo.

A última variável criada para observar o contexto segmental na queda de sílaba foi Cavidade Oral das Vogais. Como visto na seção 2, a regra de haplologia de Alkmim e Gomes (1982) tem os segmentos consonantais e vocálicos definidos diferentemente: as autoras interpretam que as consoantes devem ser coronais [-contínuo, oral], isto é, utilizam a fonologia autossegmental (cf. GOLDSMITH, 1976, 1990); para as vogais, usam a fonética, já que esses segmentos devem ter o traço [+alto]. Em outras palavras, a representação do contexto consonantal é fonológica e, para o contexto vocálico, é fonética. Neste artigo, utilizamos a geometria de traços, o que significa que tratamos do nível fonológico dos segmentos, como se observa nos fatores a seguir.

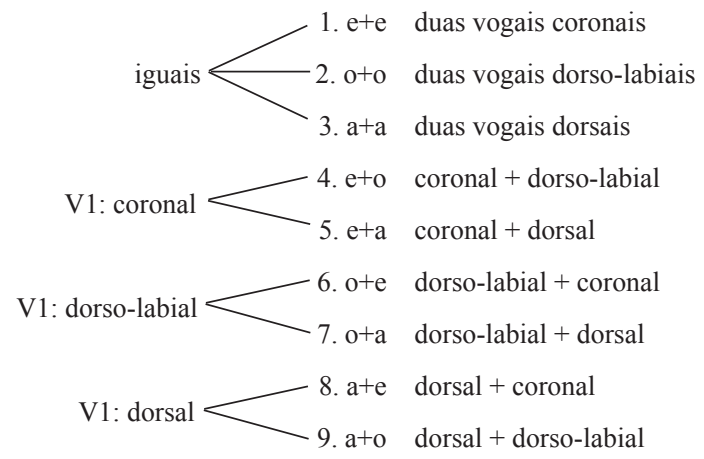

cida(DE) DE Porecatu
acontecen(DO) NO centro da cidade
chama(DA) DA unicamp
cida(DE) DO porto
tes(TE) NA ponte
calça(DO) DE sola bem grossa
advogaDO DA mãe
ca(NA) DE açúcar
estra(DA) DO ribeirão

Considerando essa variável, a hipótese que surge é que a sílaba pode ser apagada sem importar o contexto vocálico, com base nos resultados de haplologia de Pavezi (2006) e de queda de sílaba de Leal (2006, 2007), isto é, não há uma sequência vocálica que bloqueie o processo (nem mesmo /a/, como defendem Alkmim e Gomes 1982). A segunda hipótese para o contexto vocálico é investigar como os pontos de $\mathrm{C}$ das vogais podem agir na queda de sílaba. Assim como foi feito para as consoantes, levantamos a hipótese de haver vogais que são subespecificadas no português. Entre outros argumentos sobre a subespecificação das vogais, Mateus e D’Andrade (2000, p. 31) explicam que, em geral, esse segmentos têm uma maior propensão à neutralização e à epêntese. Na neutralização, as vogais tônicas $[\mathrm{e}, \mathrm{o}],[\varepsilon$, o] e $[\mathrm{i}, \mathrm{u}]$ 
alternam com $[\mathrm{i}, \mathrm{u}]$ átonos no português (como em sirvo $>\mathrm{s}[\mathrm{i}] \mathrm{rvo}$, serve $>$ $\mathrm{s}[\varepsilon] \mathrm{rve}$ e servir $>\mathrm{s}[\mathrm{e}] \mathrm{rvir}$ ); no entanto, nunca há neutralização com /a/, pois essa vogal é sempre realizada como $[\mathrm{e}]$ em posição átona. Com relação à epêntese, [i] e [e] são os elementos acrescidos em palavras no português (como em advogado>ad[e]vogado ou ad[i]vogado), enquanto que [a] nunca aparece em epênteses. Assim, com base em Mateus e D'Andrade (2000), a expectativa é que haja um favorecimento na aplicação de queda

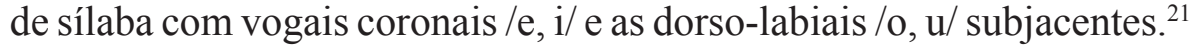

Outra hipótese para esse grupo de fatores diz respeito a contextos com vogais iguais: Battisti (2004, 2005) verificou em seus dados de Porto Alegre que sílabas com vogais iguais favorecem a haplologia. Em outras palavras, a hipótese é que o OCP age também nas vogais.

Com base nessas 4 variáveis, foram feitas 3 grandes rodadas (a geral - com as duas cidades; a rodada de Capivari; e a rodada de Campinas), alternando-se o contexto segmental, como está resumido a seguir.

\section{Resumo das rodadas 22}

Rodada 1: todas as 4 variáveis do contexto segmental, outras 5 variáveis linguísticas e as 5 variáveis sociais;

Rodada 2: variável Igualdade de Segmentos nas sílabas somente com estruturas $\mathrm{CV}$, outras 5 variáveis linguísticas e 5 variáveis sociais;

Rodada 3: Cavidade Oral das Consoantes, outras 5 variáveis linguísticas e 5 variáveis sociais;

Rodada 4: Cavidade Oral das Consoantes com distinção de [nasal], outras 5 variáveis linguísticas e 5 variáveis sociais; e

Rodada 5: Cavidade Oral das Vogais, outras 5 variáveis linguísticas e 5 variáveis sociais.

Na próxima subseção, estão os resultados para as 4 variáveis do contexto segmental nas rodadas de Capivari e de Campinas.

\footnotetext{
${ }^{21}$ A primeira vogal do contexto, ou seja, aquela sujeita ao apagamento é também o último segmento de uma palavra, como em tapeTE DA sala>tape(TE) DA sala (primeira vogal /e/ + segunda vogal/a/). Palavras terminadas em /-i/ e /-u/átonos no português não são produtivas: de fato, foram encontradas apenas 16 palavras no corpus com terminação em /-i/ e 7 terminadas em /-u/.

${ }^{22}$ Ver nota 2.
} 


\section{Resultados e discussão: Comparações entre as duas cidades}

Nesta seção, comparamos os resultados obtidos para Capivari e para Campinas, de modo a verificar se a queda de sílaba tem as mesmas características nas duas cidades ou se as regras são diferentes para a aplicação do processo.

Foram computados 5.628 tokens na fala de 48 informantes, cuja distribuição está apresentada na tabela 1.

TABELA 1 - Resultados gerais de aplicação de queda de sílaba

\begin{tabular}{c|c|c|c|c}
\hline cidade & $\mathrm{N}$ & $\%$ & total & $\%$ \\
\hline Capivari & $449 / 2150$ & 17,3 & 2599 & 46,2 \\
\hline Campinas & $737 / 2292$ & 24,3 & 3029 & 53,8 \\
\hline Total & $1186 / 4442$ & 21,1 & 5628 & \\
\hline
\end{tabular}

Fonte: Leal (2012)

O total de aplicação da queda de sílaba nas duas cidades foi $21,1 \%$, com 17,3\% de aplicação de queda de sílaba em Capivari, e $24,3 \%$, em Campinas. ${ }^{23}$ As frequências das cidades do interior paulista apresentadas são condizentes com resultados encontrados em trabalhos sociolinguísticos: Battisti $(2004,2005)$ encontrou $21 \%$ em Porto Alegre; os dados de Oliveira (2012) resultaram em $22,7 \%$ de apagamento na cidade mineira de Itaúna; Paz (2013) e Oliveira e Paz (2013) obtiveram $15 \%$ de haplologia nas cidades paraenses de Belém e Itaituba. ${ }^{24} \mathrm{E}$

\footnotetext{
${ }^{23}$ Os resultados das frequências de aplicação foram inesperados, já que a expectativa era que o processo fosse mais aplicado em Capivari do que em Campinas - há mais contextos de aplicação entre capivarianos (com base nos resultados de LEAL, 2006) do que em outros dialetos (cf. ALKMIM; GOMES, 1982; BATTISTI, 2004; PAVEZI, 2006, para haplologia). Esses resultados imprevistos foram atribuídos à variável Informantes (4 campineiros favoreceram excessivamente o processo, e 3 capivarianos desfavoreceram, isto é, 4 "empurram para cima" o favorecimento em Campinas, e 3 "puxam para baixo" o desfavorecimento em Capivari.

${ }^{24}$ Houve dois trabalhos com frequência divergente: Simioni e Amaral (2012) encontraram $40 \%$ de haplologia em 10 entrevistas (em Bagé-RS), e afirmam que esse resultado deve ser revisto "com um número maior de informantes [...]" (p. 65); Mendes (2009) encontrou 64\% de haplologia em Belo Horizonte, mas a autora não faz comentários a respeito da frequência encontrada.
} 
interessante notar que as frequências nesses trabalhos são consistentes, ainda que haja diferenças: (i) no contexto segmental: Battisti (2004, 2005), Paz (2013) e Oliveira e Paz (2013) trabalharam com contextos constituídos de /t, d/, enquanto que Leal (2012) e Oliveira (2012), com contextos consonantais mais amplos; e (ii) nos dialetos: os autores trabalharam com dialetos de lugares diferentes (e distantes) no Brasil - Paz (2013) e Oliveira e Paz (2013), com o dialeto paraense; Battisti (2004, 2005), com o dialeto gaúcho; Oliveira (2012), com o dialeto mineiro; e Leal (2012), com o dialeto paulista. A esse respeito, adotamos a afirmação de Battisti:

Os resultados do estudo realizado confirmam expectativa inicial: haplologia é regra variável de condicionamento interno, abaixo do nível da consciência, o que parece não ser peculiar apenas ao corpus analisado, mas generalizável ao português brasileiro como um todo. (BATTISTI, 2005, p. 86)

Assim, um trabalho interessante seria verificar a relação entre a queda de sílaba, saliência e consciência, examinando-a como um processo abaixo da consciência dos falantes.

Uma vez apresentadas as frequências gerais de aplicação de queda de sílaba, passamos aos resultados das variáveis do contexto segmental que foram iguais (como em Cavidade Oral das Consoantes, cf. 4.1), similares (Cavidade Oral das Consoantes com Distinção de [nasal] e Cavidade Oral das Vogais, ver 4.2) e diferentes (Igualdade de Segmentos, cf. 4.3) em Capivari e em Campinas. Incluímos nessas subseções, além de tabelas, também gráficos para facilitar a visualização dos resultados.

\subsection{Resultados iguais}

A variável Cavidade Oral das Consoantes não foi selecionada em nenhuma das rodadas. Pode-se considerar que foi um resultado igual nas duas cidades. Portanto, a cavidade oral não interfere na queda de sílaba em Capivari e nem mesmo em Campinas. E esse é um resultado inesperado, uma vez que é a cavidade oral das consoantes o nó que determina se há contexto para a queda de sílaba (isto é, se há variação ou se o processo é categórico). A solução para essa contradição foi verificada no grupo de fatores Cavidade Oral das Consoantes com Distinção de [nasal], apresentado na próxima subseção. 


\subsection{Resultados similares}

Consideramos que duas variáveis tiveram resultados similares em Campinas e Capivari: Cavidade Oral das Consoantes com Distinção de [nasal] e Cavidade Oral das Vogais.

Apresentamos os resultados dos fatores de Cavidade Oral das Consoantes com Distinção de [nasal] das rodadas de Capivari e de Campinas na tabela 2 e no gráfico 1 a seguir. ${ }^{25}$

TABELA 2 - Comparação de Cavidade Oral das Consoantes com Distinção do Traço [nasal] em Capivari e Campinas

\begin{tabular}{c|c|c|c|c|c|c}
\hline & \multicolumn{3}{|c|}{ Capivari } & \multicolumn{3}{c}{ Campinas } \\
\hline & $\mathrm{N}$ & $\% \mathrm{apl}$ & $\mathrm{p} . \mathrm{r}$. & $\mathrm{N}$ & $\%$ apl & p.r. \\
\hline $1 . \mathrm{t}+\mathrm{t}$ & $305 / 1164$ & 26,2 & 0,653 & $521 / 1399$ & 37,2 & 0,644 \\
\hline $2 . \mathrm{s}+\mathrm{s}$ & $31 / 182$ & 17 & 0,626 & $44 / 203$ & 21,7 & 0,652 \\
\hline $3 . \mathrm{p}+\mathrm{p}$ & $14 / 51$ & 27,5 & 0,777 & $4 / 37$ & 10,8 & 0,225 \\
\hline $4 . \mathrm{f}+\mathrm{f}$ & $4 / 60$ & 6,7 & 0,378 & $10 / 59$ & 16,9 & 0,605 \\
\hline $5 . \mathrm{k}+\mathrm{k}$ & $21 / 89$ & 23,6 & 0,584 & $24 / 129$ & 18,6 & 0,343 \\
\hline $6 . \mathrm{n}+\mathrm{n}$ & $74 / 1053$ & 7 & 0,3 & $134 / 1202$ & 11,1 & 0,33 \\
\hline
\end{tabular}

Fonte: Leal (2012)

${ }^{25}$ Nos gráficos, os números que aparecem abaixo dos contextos segmentais (entre vírgulas) correspondem aos totais em cada cidade - em Capivari e em Campinas, respectivamente. 
GRÁFICO 1 - Comparação da Cavidade Oral das Consoantes com Distinção do Traço [nasal] em Capivari e Campinas

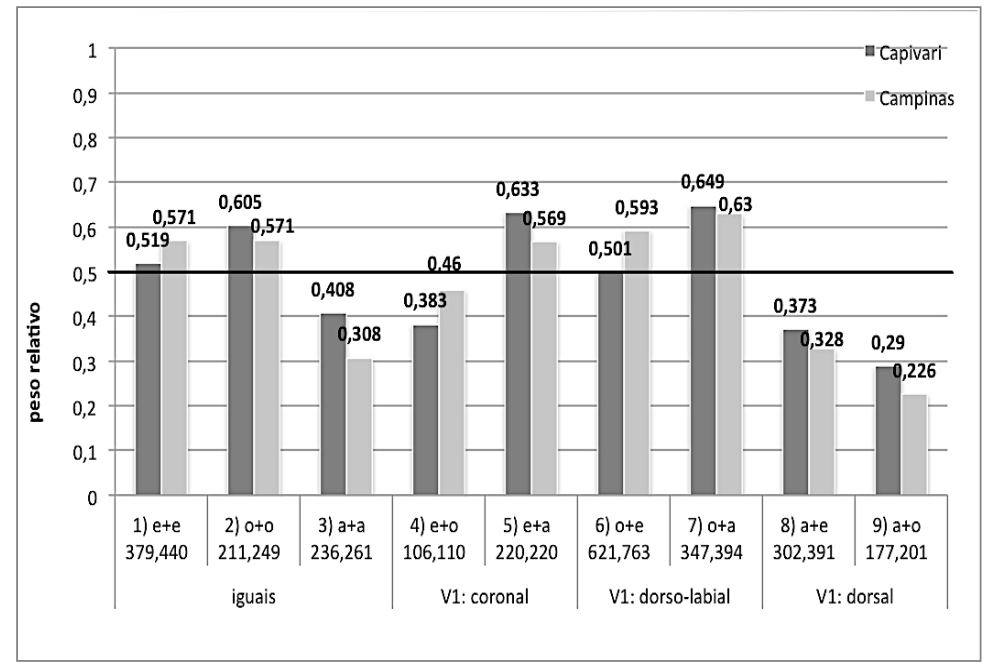

Fonte: Leal (2012)

Observando primeiramente os fatores com resultados iguais nas duas cidades, temos que as variantes das coronais (orais) favorecem a queda de sílaba, e os pesos relativos estão muito próximos (cf. contextos 1. $p=0,653$, com coronais [-contínuo], e $0,644^{26}$ e 2 . $p=0,626$ e 0,652 , com [+contínuo]), o que corrobora a hipótese inicial de subespecificação das coronais. Quanto às nasais, há um desfavorecimento do processo (ver 6. $\mathrm{p}=0,3$ e 0,33 ). Assim, esses resultados revelam que, para nasais e coronais orais, as duas cidades têm preferências (quase que) idênticas: coronais favorecem, e nasais inibem. No entanto, não podemos considerar que essa variável atua na queda de sílaba de modo idêntico nos dois diletos porque as dorsais interferem no processo de modo oposto: Capivari favorece o processo nesse contexto, enquanto que Campinas desfavorece (cf. 5. p=0,584 e 0,343). Dos contextos 3 e 4, com labiais, não podemos tirar conclusões, na medida em que não houve uma quantidade confiável de dados nas três rodadas (tanto na rodada de Capivari quanto na de Campinas). Esses resultados mostram que pode haver aplicação de queda

\footnotetext{
${ }^{26}$ Deste ponto em diante, o primeiro peso relativo que apresentamos refere-se a Capivari, e o segundo, a Campinas.
} 
de sílaba com consoantes diferentes de /t/ e /d/ - ratificando Pavezi (2006); Leal (2006, 2007); Bisol (2000); Mendes (2009); Oliveira (2012). Interessantemente, a Cavidade Oral das Consoantes com Distinção de [nasal] foi selecionada nos dois dialetos, um resultado que pode ser considerado idêntico e significa que Cavidade Oral das Consoantes com Distinção de [nasal] interfere na aplicação de queda de sílaba nas duas cidades, diferentemente de Cavidade Oral das Consoantes (sem separar segmentos [nasal]).

Outro resultado semelhante nas duas cidades foi obtido na variável Cavidade Oral das Vogais, como apresentamos na tabela 3 e no gráfico 2 .

TABELA 3 - Comparação de Cavidade Oral das Vogais em Capivari e Campinas

\begin{tabular}{c|c|c|c|c|c|c}
\hline & \multicolumn{3}{|c|}{ Capivari } & \multicolumn{3}{c}{ Campinas } \\
\hline & $\mathrm{N}$ & $\% \mathrm{apl}$ & Capivari & $\mathrm{N}$ & $\%$ apl & p.r. \\
\hline 1. $\mathrm{e}+\mathrm{e}$ & $72 / 379$ & 19 & 0,519 & $126 / 440$ & 28,6 & 0,571 \\
\hline 2. o+o & $46 / 211$ & 21,8 & 0,605 & $75 / 249$ & 30,1 & 0,571 \\
\hline 3. a+a & $25 / 236$ & 10,6 & 0,408 & $35 / 261$ & 13,4 & 0,308 \\
\hline 4. $\mathrm{e}+\mathrm{o}$ & $18 / 106$ & 17 & 0,383 & $24 / 110$ & 21,8 & 0,46 \\
\hline 5. $\mathrm{e}+\mathrm{a}$ & $54 / 220$ & 24,5 & 0,633 & $59 / 220$ & 26,8 & 0,569 \\
\hline 6. o+e & $106 / 621$ & 17,1 & 0,501 & $234 / 763$ & 30,7 & 0,593 \\
\hline 7. o+a & $83 / 347$ & 23,9 & 0,649 & $120 / 394$ & 30,5 & 0,63 \\
\hline 8. a+e & $32 / 302$ & 10,6 & 0,373 & $49 / 391$ & 12,5 & 0,328 \\
\hline 9. a+o & $13 / 177$ & 7,3 & 0,29 & $15 / 201$ & 7,5 & 0,226 \\
\hline
\end{tabular}

Fonte: Leal (2012) 
GRÁFICO 2 - Comparação da Cavidade Oral das Vogais em Capivari e Campinas

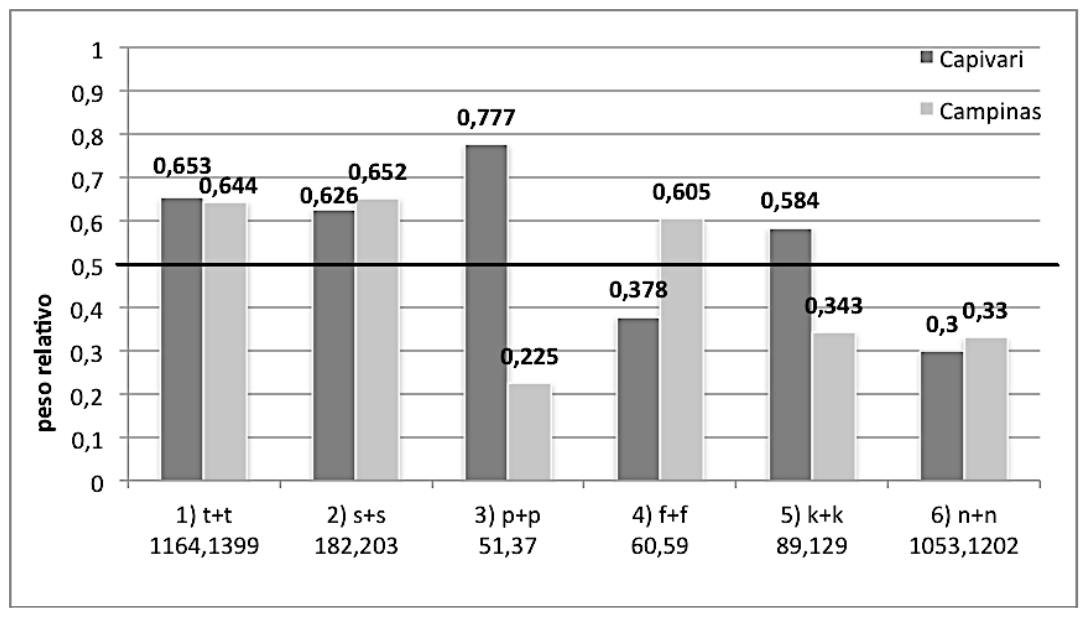

Fonte: Leal (2012)

Da variável Cavidade Oral das Vogais, podemos considerar semelhantes quatro contextos: coronal seguida de dorsal (cf. sequência 5 . $\mathrm{p}=0,633$ e 0,569), em que há um favorecimento à queda de sílaba nos dois dialetos, e o favorecimento é maior em Capivari; os outros três contextos dizem respeito a sequências com uma dorsal na primeira posição, em que o processo é desfavorecido nas duas cidades (ver 3. $\mathrm{p}=0,408 \mathrm{e}$ 0,$308 ; 8 . p=0,373$ e 0,328 ; e $9 . p=0,29$ e 0,226 ), mas podemos notar que esses contextos são mais aceitos em Capivari do que em Campinas. Anteriormente, vimos que o ponto de $\mathrm{C}$ [dorsal] das consoantes favorece a queda de sílaba em Capivari e desfavorece em Campinas. Assim, ao utilizar a geometria de traços na queda de sílaba, foi possível verificar resultados de consoantes e vogais com um mesmo comportamento: o traço [dorsal] interfere no processo de modo a favorecer em Capivari e a desfavorecer em Campinas, isto é, há uma aceitabilidade maior de apagamento com esses segmentos em Capivari.

No que concerne às diferenças entre as duas cidades, nas sequências com duas coronais (ver contexto 1 no gráfico 2) e com uma dorso-labial seguida de uma coronal (cf. 6, com $\mathrm{p}=0,501$ e 0,593), as tendências são diferentes: esses contextos são neutros em Capivari, mas favorecem a queda de sílaba em Campinas. 
Do contexto de uma coronal seguida de uma dorso-labial (cf. 4. $\mathrm{N}=106$ e $\mathrm{N}=110$ ), nada podemos concluir, em consequência do baixo número de tokens nesses fatores para as duas cidades.

Esses resultados confirmam a primeira hipótese, já que o contexto vocálico não importa para a implementação da queda de sílaba no sentido de bloqueá-la em Capivari e em Campinas, incluindo vogais dorsais na primeira sílaba - corroborando Pavezi (2006), Leal $(2006,2007)$ e Oliveira (2012), e vai de encontro à proposta de Alkmim e Gomes (1982).

Na seção 3, levantamos a hipótese de que o OCP pode atuar nos contextos vocálicos, de modo a favorecer o processo se houver identidade das vogais. Essa hipótese foi refutada, como podemos observar nos contextos com duas vogais iguais: o fator 1 com duas coronais é neutro em Capivari e favorecido em Campinas; o contexto 2 com duas dorso-labiais favorece o processo em ambas as cidades; e o fator $3 \mathrm{com}$ duas dorsais desfavorece o processo, também em ambas as cidades. Os resultados com vogais diferentes também confirmam que o OCP não rege a queda de sílaba: nos contextos com uma coronal na primeira posição (como em 1. $p=0,519$ e 0,571; e 5) e naqueles com uma dorso-labial na primeira sílaba (sequências 2,6 e $7 . p=0,649$ e 0,63 ), a queda de sílaba é favorecida; nos contextos com uma dorsal na primeira posição $(3,8$ e $9 \cdot p=0,29$ e 0,226$)$ há desfavorecimento do processo. A exceção a esse padrão é na sequência 4 com uma vogal coronal seguida de uma dorso-labial porque seu número de tokens foi baixo, com um total de $\mathrm{N}=42 / 216$ nas duas cidades. Assim, esses resultados de contextos com vogais iguais e vogais diferentes indicam que o importante é o ponto de $\mathrm{C}$ da vogal sujeita à queda (isto é, da primeira sílaba).

Podemos, portanto, afirmar que a igualdade das vogais não é uma característica importante para a queda de sílaba, e o OCP não atua em nenhum dos dialetos, resultado que vai de encontro aos de Battisti (2004, 2005), Paz (2013) e Oliveira e Paz (2013) e corrobora os de Oliveira, que explica:

[...] o apagamento da vogal seguida de consoante está associado à altura da vogal, sendo as vogais mais altas as mais apagadas por serem mais reduzidas do ponto de vista articulatório. (OLIVEIRA, 2012, p. 171)

Concluímos que a variável Cavidade Oral das Vogais atua na queda de sílaba de modo similar nas duas cidades: são diferentes nos 
fatores 1 e 6 (são contextos neutros em Capivari e favorecedores em Campinas); semelhantes em contextos 5 (há favorecimento nas duas cidades, sendo um pouco maior em Capivari) e semelhantes também em contextos com dorsais (desfavorecem, com uma aceitação maior entre os capivarianos do que entre os campineiros); e as sequências 2 e 7 são iguais nas duas cidades (há favorecimento do processo, com pesos relativos próximos).

Finalmente, o que parece ser relevante para o processo é o ponto de $\mathrm{C}$ da vogal sujeita ao apagamento, e não a igualdade desses segmentos:

(i) Com coronais na primeira sílaba, o contexto 1 mostra neutralidade entre capivarianos e favorecimento entre campineiros; o fator 5 favorece a queda de sílaba em ambas as cidades; e nada concluímos com o fator 4 , devido ao baixo número de dados.

(ii) Para dorso-labiais na primeira sílaba, o fator 2 favorece o processo nas duas cidades; no fator 6 , há neutralidade em Capivari e favorecimento em Campinas; há favorecimento nos dois dialetos com o fator 7 .

(iii) Com dorsais na primeira sílaba, há desfavorecimento da queda de sílaba nos três fatores 3,8 e 9 .

Assim, pode haver favorecimento ou neutralidade com vogais coronais e dorso-labiais na primeira sílaba, enquanto que as dorsais nessa posição desfavorecem o processo nas duas cidades.

\subsection{Resultados diferentes}

A variável Igualdade de Segmentos só foi selecionada em Campinas, o que significa que a igualdade entre os segmentos nas sílabas não é importante para Capivari. É por essa razão que os resultados de Capivari aparecem com preenchimentos diferentes para indicar que a variável não foi selecionada na rodada 1 , mas, sim, na rodada 2 , conforme demonstrado na tabela 4 e no gráfico 3 . 
TABELA 4 - Comparação de Igualdade de Segmentos em Capivari e Campinas

\begin{tabular}{c|c|c|c|c|c|c|c}
\hline \multicolumn{2}{c|}{} & \multicolumn{3}{c|}{ Capivari } & \multicolumn{3}{c}{ Campinas } \\
\hline \multirow{2}{*}{ Cs iguais } & $\mathrm{N}$ & $\%$ apl & p.r. & $\mathrm{N}$ & $\%$ apl & p.r. \\
\cline { 2 - 8 } & $1 . \mathrm{C}=\mathrm{V}=$ & $34 / 120$ & 28,3 & 0,619 & $60 / 130$ & 46,2 & 0,644 \\
\hline \multirow{3}{*}[\text{voz}]{} & 2. C=V\# & $105 / 445$ & 23,6 & 0,609 & $153 / 443$ & 34,5 & 0,572 \\
\cline { 2 - 8 } & 3. C\#vozV= & $37 / 157$ & 23,6 & 0,556 & $59 / 166$ & 35,5 & 0,495 \\
\hline \multirow{3}{*}{ nasal] } & 4. C\#vozV\# & $91 / 348$ & 26,1 & 0,633 & $141 / 410$ & 34,4 & 0,499 \\
\cline { 2 - 8 } & 6. C\#nasalV= & $9 / 66$ & 13,6 & 0,363 & $11 / 88$ & 12,5 & 0,372 \\
\hline [ant,dist] & 7. C\#distr. & $1 / 24$ & 4,2 & 0,299 & $1 / 29$ & 3,4 & 0,1 \\
\hline
\end{tabular}

Fonte: Leal (2012)

GRÁFICO 3 - Comparação da Igualdade de Segmentos em Capivari e Campinas

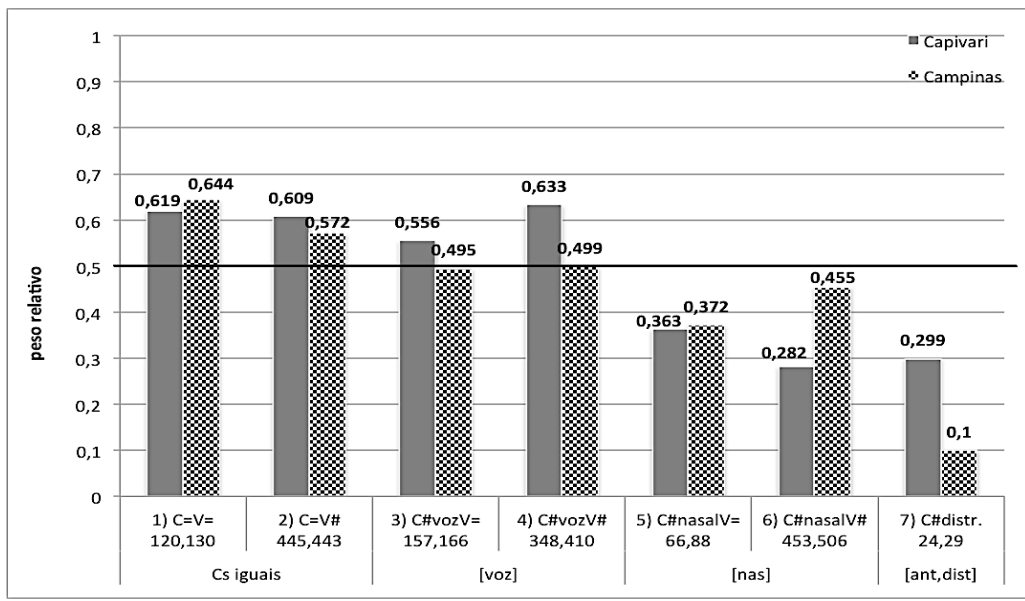

Fonte: Leal (2012)

Nos resultados para Igualdade de Segmentos expostos na tabela 4 e no gráfico 3 , podemos observar que o processo é favorecido com sílabas idênticas (cf. contexto 1.p=0,619 e 0,644), em ambas as cidades; também há favorecimento no fator com consoantes iguais e vogais diferentes em ambas as cidades (cf. 2. p=0,609 e 0,572). Em outras 
palavras, se as sílabas tiverem as mesmas consoantes, sendo as vogais iguais ou diferentes, não há mudança na tendência. Assim, a hipótese de o OCP regular a queda de sílaba foi confirmada em parte: sílabas iguais favorecem o processo, porém sílabas com consoantes iguais, mas com vogais diferentes também favorecem. Dessa forma, os resultados revelam que as consoantes são regidas pelo OCP, diferentemente das vogais, como foi visto na variável Cavidade Oral das Vogais. Para o traço [vozeamento], os fatores $3(p=0,556$ e 0,495$)$ e $4(p=0,633$ e 0,499$)$ indicam favorecimento em Capivari e neutralidade em Campinas. Quanto aos contextos nasais, há desfavorecimento nas duas cidades, tanto com vogais iguais quanto com vogais diferentes (5. $\mathrm{p}=0,363$ e 0,372 ; e 6 . $\mathrm{p}=0,282 \mathrm{e} 0,455)$. Finalmente, no que concerne às diferenças consonantais nos traços [anterior, distribuído], nada podemos concluir, uma vez que o número de tokens desse fator foi muito baixo (7. $\mathrm{N}=24$ em Capivari e $\mathrm{N}=29$ em Campinas).

Ao comparar os três pares $(1,2)$ (indicados por $C$ s iguais na tavela 4 e no gráfico 3); $(3,4)$ [voz]; e $(5,6)$ [nas], observamos que, em Capivari, os pares Cs iguais e [voz] favorecem o processo, enquanto que o par [nas] desfavorece; em Campinas, Cs iguais favorecem o processo, o par [voz] é neutro, e o par [nas] desfavorece. Assim, as tendências mostram que as vogais parecem inertes ao processo, mas os traços [vozeamento] $\mathrm{e}$ [nasal] interferem de modo diferente em Capivari e em Campinas.

Mesmo que os resultados de Igualdade de Segmentos tenham poucas diferenças entre as cidades, chamamos a atenção para o fato de que essa variável só foi selecionada em Campinas e concluímos que ter sílabas segmentalmente iguais ou diferentes não é relevante para a aplicação do processo em Capivari. Assim, a variável Igualdade de Segmentos tem efeitos diferentes nas duas cidades.

\subsection{Duas cidades, duas regras?}

O principal ponto que buscamos investigar foi se as propriedades de queda de sílaba são iguais ou diferentes em Capivari e Campinas.

Um resultado igual nas duas cidades foi na variável Cavidade Oral das Consoantes, que não foi selecionada em nenhuma das rodadas - ou seja, se separadas somente pela cavidade oral, as consoantes não interferem no processo, tanto em Capivari quanto em Campinas. Já que o ponto de $\mathrm{C}$ e o valor para [contínuo] (isto é, a cavidade oral das 
consoantes) determinam qual é o contexto de queda de sílaba, esse resultado foi inesperado. Entretanto, pudemos observar que, se a variável Cavidade Oral das Consoantes nunca foi selecionada, é importante separar as nasais. Desse modo, a variável Cavidade Oral das Consoantes com Distinção de [nasal] passou a ser selecionada.

Com relação a resultados semelhantes, houve duas variáveis: na Cavidade Oral das Consoantes com distinção do traço [nasal], foi visto que há tendências e produtividades praticamente idênticas para coronais orais e para nasais: o primeiro tipo de segmento é favorecedor, e o segundo, desfavorecedor. No entanto, as tendências são opostas para dorsais: há favorecimento em Capivari e desfavorecimento em Campinas, o que indica duas regras distintas. A segunda variável que teve resultados semelhantes nas duas cidades foi Cavidade Oral das Vogais, em que verificamos: (i) igualdades, com favorecimento nos contextos [dorso-labial + dorso-labial] e [dorso-labial + dorsal], fatores que têm uma mesma tendência e produtividade; (ii) semelhanças, como nos contextos com uma [dorsal] na primeira sílaba e contextos [coronal + dorsal], casos que desfavorecem o processo, isto é, a tendência é a mesma, mas a produtividade é diferente; e (iii) finalmente, os contextos [coronal + coronal] e [dorso-labial + coronal] são diferentes nas duas cidades, uma vez que há uma neutralidade em Capivari e um favorecimento em Campinas. Observando-se (i), (ii) e (iii), concluímos que Cavidade Oral das Vogais tem efeito diferente nas duas cidades.

Quanto a diferenças, a variável Igualdade de Segmentos é distinta nas duas cidades, já que foi selecionada somente em Campinas.

Concluímos que há duas restrições segmentalmente distintas de queda de sílaba para as cidades de Capivari e Campinas. ${ }^{27}$

De modo geral, a queda de sílaba pode ser implementada do seguinte modo, de acordo com Leal:

(26) A queda de sílaba se dá se as consoantes envolvidas no processo tiverem o mesmo ponto de $\mathrm{C}$ e o mesmo valor para o traço [contínuo] (LEAL, 2006, p. 165).

\footnotetext{
${ }^{27}$ Oliveira (2012) defende que a haplologia e a elisão silábica são um mesmo fonológico. Essa questão, que vai de encontro aos resultados de Leal (2006, 2007, 2012) e deste artigo, será tratada em trabalhos futuros.
} 
Com relação a essa regra, Oliveira questiona:

[...] para a haplologia, importa o compartilhamento dos traços terminais do nó cavidade oral (como propõe LEAL, 2006) ou no nó raiz? Caso o nó relevante seja o nó cavidade oral, os traços [sonoro] e [nasal] não deveriam interferir no processo. (OLIVEIRA, 2012, p. 215)

Essa afirmação de Oliveira (2012) mostra que ainda restam questões muito complexas a serem investigadas a respeito da queda de sílaba. E optar pelo nó de cavidade oral ou pelo nó de raiz não soluciona a questão sobre qual é o lugar dessa regra (cf. subseção 9.4 de LEAL, 2012).

Uma possibilidade para resolver essa questão foi proposta em Leal (2012) do seguinte modo: enquanto pontos de C e/ou [contínuo] diferentes bloqueiam o processo, uma diferença em [ \pm vozeamento] ou a presença de [nasal] não bloqueia o processo, apenas desfavorece-o ou mantém-no neutro. Assim, uma forma de dar conta tanto de dados quanto de teoria seria interpretar que há, pelos menos, duas "fases" na queda de sílaba: $1^{\text {a }}$ fase: deve-se certificar que a cavidade oral das consoantes, isto é, o ponto de $\mathrm{C}$ e [ \pm contínuo], é a mesma; $2^{\text {a }}$ fase: eleva-se novamente ao nó de raiz, para que [nasal], [ \pm vozeado] e [coronal, dorsal e labial] possam atuar com favorecimento, neutralidade ou desfavorecimento.

Ainda segundo Leal (2012), há dois problemas teóricos nessa interpretação de duas "fases": (A) contraria o princípio de que regras fonológicas executam uma única operação (CLEMENTS; HUME, 1995: 250), uma vez que, primeiramente, deve-se identificar a cavidade oral (o local da regra); em seguida, sobe-se novamente ao nó de raiz, para que os traços ditem favorecimento, neutralidade ou desfavorecimento. (B) Vai de encontro também ao princípio de que, se um processo fonológico é aplicado num determinado nó, aplica-se também a todos os seus nós dominados (cf. CLEMENTS; HUME, 1995, p. 251); na segunda fase, em que o processo "retorna" ao nó de raiz para determinar a tendência do processo, deve-se ignorar [ \pm contínuo], pois esse traço determina a possibilidade de aplicação ou o bloqueio - nunca a tendência. ${ }^{28}$

\footnotetext{
${ }^{28}$ Neste artigo, não apresentamos uma formalização da regra de queda de sílaba (com base na geometria de traços) em consequência da dificuldade que ainda parece existir em capturar a regra. Agradeço ao parecerista anônimo por nos chamar a atenção a esse fato.
} 
De forma resumida, podemos interpretar que há duas grandes restrições para a implementação do processo: (i) primeiramente, o nó cavidade oral deve ser o mesmo, isto é, ponto de $\mathrm{C}$ e [contínuo] devem ser os mesmos; de outra forma, há bloqueio; (ii) num segundo momento, os traços [nasal], [vozeado] e, novamente, o ponto de $\mathrm{C}$ ditam a tendência da regra.

Em vista do que apresentamos nesta subseção, vemos que há ainda uma grande dificuldade em capturar a queda de sílaba. Por outro lado, estudos sobre esse processo fonológico podem contribuir para a teoria fonológica.

\section{Considerações finais}

O principal objetivo neste artigo foi verificar se a queda de sílaba tem características segmentais iguais ou diferentes nos dialetos de Capivari e de Campinas.

Observamos que há possibilidade de aplicação do processo com segmentos diferentes de /t/ e /d/, corroborando Pavezi (2006), Leal (2006, 2007), Mendes (2009) e Oliveira (2012), diferentemente do que afirmam Alkmim e Gomes (1982). Ainda para as consoantes, constatamos que capivarianos e campineiros têm tendências muito parecidas para coronais orais e para [nasal]: as coronais favorecem o processo (confirmando a subespecificação das coronais), enquanto que nasais desfavorecem ainda, encontramos resultados de que pode haver aplicação com nasais; novamente, esses resultados corroboram Pavezi (2006), Leal (2006, 2007), Mendes (2009) e Oliveira (2012). Vimos ainda que as cidades preferem uma configuração em que os segmentos nasais são levados em conta, já que só foram selecionadas as variáveis em que esse traço foi examinado em separado. Entretanto, as cidades divergem no traço [dorsal]: há um favorecimento do processo para capivarianos e um desfavorecimento para campineiros.

Quanto ao traço [vozeamento], observamos que esse traço não bloqueia o processo, o que ratifica Alkmim e Gomes (1982), Tenani (2002), Pavezi (2006) e Leal (2006, 2007); se as consoantes forem idênticas, isto é, com um mesmo [vozeamento], o processo é favorecido; e se as consoantes forem diferentes nesse traço, há uma neutralidade ao processo. 
Para as vogais, pudemos observar que não há bloqueio com dorsais, o que corrobora Pavezi (2006) e Leal $(2006,2007)$ e vai de encontro a Alkmim e Gomes (1982); interessantemente, esses contextos de bloqueio para as autoras desfavorecem o processo em ambas as cidades. Outros resultados para vogais mostraram que houve: (i) diferenças, com coronais e com dorso-labial seguida de coronal, há um favorecimento em Campinas e uma neutralidade em Capivari; (ii) semelhanças: uma coronal seguida de uma dorsal favorecem o processo nos dois dialetos; outra semelhança é com vogais dorsais, já que há um desfavorecimento nas duas cidades; e (iii) igualdades: com duas dorso-labiais e com dorsolabial seguida de dorsal, há favorecimento, com pesos relativos próximos, em ambas as cidades.

Concluímos que as cidades de Capivari e de Campinas têm regras diferentes de aplicação de queda de sílaba, no que concerne ao contexto segmental.

\section{Agradecimentos}

Agradeço aos pareceristas anônimos pelos comentários e sugestões. Os problemas remanescentes são de minha responsabilidade. Agradeço ainda à CAPES e à FAPERGS pelo auxílio financeiro - no doutorado, à CAPES, e no pós-doutorado, à CAPES e FAPERGS, com uma bolsa DOCFIX).

\section{Referências}

ALKMIM, T.M.; GOMES, C.A. Dois fenômenos de supressão de segmentos em limite de palavra. Ensaios de Linguística, v. 7, p. 43-51, 1982. Doi: http://dx.doi.org/10.17851/0101-3548.4.7.43-51.

BATTISTI, E. Haplologia sintática e efeitos da economia. Organon, UFRGS, Porto Alegre, v. 18, n. 36, p. 31-39, 2004. Doi: http://dx.doi. org/10.22456/2238-8915.31152

BATTISTI, E. Haplologia no português do sul do Brasil: Porto Alegre. Letras de Hoje, PUCRS, Porto Alegre, v. 40, n. 3, p. 73-88, 2005.

BISOL, L. O troqueu silábico no sistema fonológico (Um adendo ao artigo de Plínio Barbosa). D.E.L.T.A., PUCSP, São Paulo, v.16, n. 2, p. 403-413,2000. Doi: http://dx.doi.org/10.1590/S010244502000000200007. 
BOERSMA, P.; WEENINK, D. Praat: doing phonetics by computer (Versão 5.1.23), 2010. Disponível em: <http://www.praat.org/>.

CLEMENTS, G.N.; HUME, E. The internal organization of speech sounds. In: GOLDSMITH, J. (Ed.). The Handbook of Phonological Theory. Oxford: Basil Blackwell, 1995. p. 245-306.

CRYSTAL, D. [1985]. Dicionário de linguística e fonética. Trad. [da 2a ed. inglesa de 1985] Maria Carmelita Pádua Dias. Rio de Janeiro: Jorge Zahar, 2003.

FIKKERT, P.; LEVELT, C. How does Place fall into Place? The lexicon and emergent constraints in children's developing phonological grammar. Manuscript, January 2006.

GOLDSMITH, J. Autosegmental Phonology. 1976, 280f. Dissertation (Ph.D.) - MIT, Cambridge MA, 1976.

GOLDSMITH, J. Autosegmental and Metrical Phonology. Oxford: Blackwell, 1990.

LABOV, W. Sociolinguistic patterns. Philadelphia: University of Pensilvania Press, 1972.

LABOV, W. Principles of linguistic change. Malden and Oxford: Blackwell Publishers, 1994. v. I: Internal factors.

LABOV, W. Principles of linguistic change. Malden and Oxford: Blackwell Publishers, 2001. v. II: Social factors.

LEAL, E.G. Elisão silábica e haplologia: aspectos fonológicos do falar da cidade paulista de Capivari. 2006, 165f. Dissertação (Mestrado em Semiótica e Linguística Geral) - Universidade de São Paulo, FFLCH, São Paulo, 2006.

LEAL, E. G. A queda da sílaba: análise do contexto consonantal pela geometria de traços. Revista Virtual de Estudos da Linguagem-ReVEL, Edição especial, n. 1, 2007. Disponível em:<www.revel.inf.br>.

LEAL, E. G. Teoria fonológica e variação: a queda de sílaba em Capivari e em Campinas. 2012. 242f. Tese (Doutorado em Semiótica e Linguística Geral) - FFLCH-USP, São Paulo, 2012. 
LEBEN, W. Suprasegmental Phonology. 1973. Dissertation (Ph.D.) MIT, Cambridge MA, 1973.

MATEUS, M.H.; D'ANDRADE, E. The phonological system of Portuguese. In: MATEUS, Maria H.; D'ANDRADE, E. The phonology of Portuguese. Oxford; New York: Oxford University Press, 2000. p. 29-37.

MCCARTHY, J. On stress and syllabification. Linguistic Inquiry, The MIT Press, v. 10, p. 443-465, 1979.

MCCARTHY, J. Feature geometry and dependency: a review. Phonetica, v. 45, p. 84-108, 1988. Doi: https://doi.org/10.1159/000261820

MENDES, R.M.G. A haplologia no português de Belo Horizonte. 2009. Dissertação (Mestrado) - Pontifícia Universidade Católica de Minas Gerais, Belo Horizonte, 2009.

NESPOR, M.; VOGEL, M. Prosodic phonology. Dordrecht: Foris Publications, 1986.

OLIVEIRA, A. J. 'Comendo o final das palavras': Análise variacionista da haplologia, elisão e apócope em ltaúna / MG. 2012. Tese (Doutorado) - UFMG, Belo Horizonte, 2012.

OLIVEIRA, A. J.; VIEGAS, M.C. Casos especiais de elisão silábica: uma contribuição aos estudos de gramaticalização. In: VIEGAS, M. C. (Org.). Minas é singular. Belo Horizonte: Faculdade de Letras da UFMG, 2013.

OLIVEIRA, M.; PAZ, F. Haplologia na região amazônica: imagens preliminares. Estudos de Lingüistica Galega, Universidade de Santiago de Compostela, v. 5, p. 69-87, 2013.

PARADIS, C.; PRUNET, J. F. Phonetics and phonology: the special status of coronals. San Diego: Academic Press, 1991. v. 2.

PAVEZI, V. C. A haplologia na variedade paulista. 2006. Dissertação (Mestrado) - Unesp, São José do Rio Preto, 2006.

PAZ, F. H. S. Haplologia no falar paraense. 2013. 116 f. Dissertação (Mestrado) - Universidade Federal do Pará, Belém, 2013.

PRINCE, A.; SMOLENSKY, P. Optimality theory: constraint interaction in generative grammar (ROA Version 8/2002). Rutgers, NJ: Rutgers Center for Cognitive Science, 1993. 
SÁ NOGUEIRA, R. Tentativa de explicação dos fenômenos fonéticos em português. Lisboa: Livraria Clássica Editora, 1958.

SANKOFF, D.; TAGLIAMONTE, S.; SMITH, E. Goldvarb X: A variable rule application for Macintosh and Windows. Toronto: Department of Linguistics, University of Toronto, 2005.

SIMIONI, T.; AMARAL, F.U. A haplologia e o princípio do contorno obrigatório. Revista do GELNE, UFRN, v.13, p. 53-67, 2011.

TENANI, L. E. Domínios prosódicos no português do Brasil: implicações para a prosódia e para a aplicação de processos fonológicos. 2002. Tese. (Doutorado) - UNICAMP, Campinas, 2002. 